\title{
Characteristics of the Re-Entry Experiences of Returning Saudi International Students after Studying Abroad
}

\author{
Naif Daifullah Z Alsulami ${ }^{1}$ \\ ${ }^{1}$ Assistant professor, Faculty of education, Umm Al-Qura University, Saudi Arabia \\ Correspondence: Naif Daifullah Z Alsulami, Assistant professor, Faculty of education, Umm Al-Qura University, \\ Saudi Arabia
}

Received: March 26, 2020

Accepted: April 24, 2020

Online Published: May 12, 2020

doi:10.5430/ijhe.v9n3p309

URL: https://doi.org/10.5430/ijhe.v9n3p309

\begin{abstract}
The purpose of this research is to describe the characteristics of the re-entry experiences of Saudis returning to Saudi Arabia after studying abroad. The total number of participants in the study was 21 , consisting of 13 male and 8 female participants returning from studying in the U.S., U.K., and Australia. By conducting semi-structured individual interviews with the participants, the findings showed six themes including motivations for returning home, preparing for returning home, feelings on returning home, the nature of relationships with family, the nature of relationships with friends and sense of belonging. Implications of the findings and directions for future research are provided.
\end{abstract}

Keywords: international education, comparative education, re-entry experiences, returning home, studying abroad, saudi international students.

\section{Introduction}

One of the effects of globalisation is cross-border mobility, which has become a reality of daily life for many people (Casinader, 2012). People from various languages, ethnicities and cultures have the means either to travel across the oceans to either live permanently, as tourists, as immigrants or refugees, or to live temporarily as business people, missionaries and, most importantly for the purpose of this research, as international students (Arthur, 2003). Typically, the duration of stay for those who reside abroad temporarily is between six months and five years (Szkudlarek, 2010); hence, it is not classified as permanent migration and returning home is a predictable chapter in the journey.

There are different types and categories of re-entry found in the literature: cross-cultural re-entry, such as re-entry of missionaries (Green, 2008; Walling et al., 2006; Weber, 2009); re-entry within a culture, such as prisoners' re-entry to the community after spending time in prisons (Dickey \& Klingele, 2004; Hattery, \& Smith, 2010; La Vigne, 2006; Pedlar, Arai, Yuen, \& Fortune, 2018; Ward, 2017); and re-entry of learners who dropped out of school and subsequently re-enrol into schools (Alika \& Ohanaka, 2013; Brown, 2010; Musita, Ogange, \& Lugendo, 2018). However, the most common type of re-entry found in the literature is re-entry from international education (Allison et al., 2012; Butcher, 2002; Chamove \& Soeterik, 2006; Christofi \& Thompson, 2007; Dettweiler et al., 2015; Gill, 2010; Hadis, 2005; Jandová, 2014; Kartoshkina, 2015; Larson, 2006; MacDonald \& Arthur, 2004; Pitts, 2016; Pritchard, 2011; Welsh, 2015; Wielkiewicz \& Turkowski, 2010).

Many studies explored the entry experiences of international students into their host countries (Alsulami,2018; Mukthyala, 2013; Novera, 2004), however, few studies have explored the international students' re-entry experiences. Szkudlarek (2010) and Young (2014) deemed that issues related to re-entry experience to home countries that are often neglected in academia, are as crucial as those associated with the host country while studying abroad.

A part of the re-entry experiences is exploring the characteristics of re-entry for returning Saudi international students after studying abroad. Despite Saudi Arabia being one of the largest countries sponsoring its students to study abroad, little is known about how Saudi returnees describe the characteristics of their re-entry to Saudi Arabia after studying abroad? This study is, therefore-significant for both the Saudi government and Saudi returnees in order to explore the issues of re-entry, and help returnees smoothly re-adapt to their home culture.

\section{Literature Review}

The literature reports themes associated with characteristics of re-entry, that include motivations for returning home, 
feelings upon returning home, the relationship between returnees and their families and the relationship between returnees and their friends (Bass, 2006; Beverley, 2007; Dentakos et al., 2017; Hawthorne \& Hamilton, 2010). The motivations of students returning home shape the characteristics of their re-entry. These motivations can assist returnees to re-adapt smoothly to their home culture. For instance, if one of the re-entry motivations is the easiness of finding a job in the home culture, unlike unemployed returnees, this job will help returnees re-adapt more smoothly as a result of job stability. If the motivation is to reunite the strong relationship with family, this family is likely to help returnees overcome the re-entry challenges and to re-adapt smoothly. Many studies indicated that most international students planned to stay in their host countries and felt reluctant to go back home (Bass, 2006; Beverley, 2007; Dentakos et al., 2017; Hawthorne \& Hamilton, 2010). Bass' (2006) study reported that 33 per cent of international students who completed their studies obtained permanent residency-(PR) status and remained in Australia. Beverley (2007) surveyed international students undertaking a second-year accounting unit at a Melbourne-based university. The result showed that 84 per cent of the sample planned to seek permanent residency in Australia. Other studies showed that international students returned to their home countries to apply what they have learned overseas. Gill's (2010) empirical study with eight Chinese students who returned to China after spending years in the U.K., reported that none of the participants planned to emigrate, and motivation for coming back to China was to improve their country towards modernisation.

The feelings upon returning home are characterised by expectations of easiness or difficulty around the re-adjustment process. By way of illustration, feelings of sadness about re-entry might be an indicator of a difficult re-adjustment. Recognising these feelings might be helpful in approaching returnees and providing suitable help for them. Although international students will return to their familiar culture, findings of some research projects show that the process of returning home is a major underlying concern for them (Arthur, 2003; Ryan \& Twibell, 2000). Ryan and Twibell (2000) investigated stress and concerns amongst American college students who studied abroad, mainly in European countries, during an academic year with the International Student Exchange Program. It was found that the process of returning home was the greatest stressor for the students. Conversely, some students reported that their appreciation for their home culture was increased by studying abroad. The feelings of returnees about homecoming varied, from feeling happy or excited, or sad to leave the host country. Some returnees had distinctly positive feelings about their homecoming and expressed their happiness to return and reconnect with their families and friends, (2010). However, Arthur's (2003) study showed that feelings regarding return were generally combined with a sense of loss about leaving the new lifestyle of the host country to which international students may have adapted themselves.

The nature of family relationships is part of the characteristics of re-entry yet determining the meaning of family is crucial in understanding the characteristics of this relationship after returning home. Does the meaning of 'family' refer to the nuclear family or extended family? While Butcher (2002) specified the relationship with family as the relationship of returnees to their parents, Gill (2010) did not define 'family' in his study. In this research, bearing in mind the major social connections in Saudi Arabia and the central role of family in Saudi culture (Ibn Sonaitan, 2008), family is the extended family, including parents, wife, children, brothers, sisters, uncles and nieces. The relationship between returnees and their families is critical in facilitating the re-adjustment of returnees. Some returnees expressed good relationships with their families and others did not. Gill's (2010) research reported that all participants' re-entry experiences began with a warm welcome from family, announcing good relationships with them, whilst some returning international students reported unstable relationships with their families. Butcher (2002) examined the problems of re-entry of international students from East Asia after studying in New Zealand. The study revealed that participants experienced tensions between themselves and their parents due to the changes in their worldviews. In many cases, their families did not appreciate or understand these changes. Perceptions of families and their roles in individuals' lives from Western perspectives are very different from Saudi perspectives, as in Saudi the role of family is critical and it has great power in shaping and re-shaping individual life (Alomar, 2008). The strong role of families in a culture might be considered as a double-edged sword as it could be helpful in solving re-entry challenges, or it might be a negative factor in terms of not welcoming changes brought by returnees, if they have changed.

The nature of relationships with friends is one of the forms of the re-entry 'characteristics'. The concept of friendship and how important and deep it is might differ from culture to culture. However, having friends is important for all people (Caine, 2009; Regan, 2011). Before studying abroad international students may have friends with similar backgrounds and experiences. After having an international experience while studying abroad and then returning home, the changes experienced while away might not be welcomed by their original friends and may contribute to unstable relationships. The original friends of returnees might see their friends as acquiring international certificates 
and respect them more, therefore, those returnees can influence their friends positively. Most of the literature related to the relationship between returnees and their friends seems to be negative (Allison et al., 2012; Brabant, et.al's, 1990; Butcher, 2002). For example, Brabant, Palmer, \& Gramling's (1990) research investigating the common problems faced by foreign students from Lebanon, Venezuela, Nigeria and Switzerland, followed their sojourn at an American campus. Surveys of 66 students showed that participants experienced some problems in their daily lives, and they expressed unstable relationships with their friends because of the changes they experienced. Similar to Butcher's (2002) study, Brabant, et.al's (1990) study found that a large number of the returnees lost many of their friends. Possible reasons for these findings were explained by Allison et al. (2012) claiming that the problems with unstable relationships with friends after returning home were because friends seemed to be uninterested in the exciting and enlightening experiences of the participants studying abroad.

Whilst these four themes have been briefly explored, other themes may be explored by different researchers, and the data of their studies could be classified under the umbrella of the 'characteristics of the re-entry'. What is notable is the gap in the characteristics of the re-entry of Saudi returnees. Understanding the characteristics and conditions of re-entry is crucial for helping returnees re-adapt smoothly to their original culture.

\section{Methodology}

The objective of this study was to gain an in-depth understanding of how Saudis returning to Saudi Arabia from studying abroad described the characteristics of their re-entry. The study was theoretically underpinned by a constructivist paradigm (Darlaston-Jones, 2007; Flick, 2006; Miller \& Glassner, 2004) employing a qualitative case study (Stake, 2005, Yin, 2014). The total number of participants in the study was 21 Saudi returnees, consisting of 13 male and 8 female participants returning from studying in the U.S., U.K., and Australia. These 21 returnees currently work at the academia at Umm Al-Qura University in Mecca, Saudi Arabia. Face-to-face semi-structured individual interviews were conducted with all male participants, however, due to the gender segregation policy in Saudi Arabia (Alhazmi, 2015; Alhazmi \& Nyland, 2015; Van Geel, 2016) individual interviews with the 8 females occurred via video conferencing.

Casinader (2014) suggested that the choice of language for an interview and using common language between interviewer and interviewees is important because it 'offered greater facility for the researcher to develop the sequence of questions in a more fluid, organic manner, exploring the ideas that might arise from responses during the interview' (p. 89). All of the recorded interviews proceeded in Arabic because it was everyone's first language, and it enabled better expression and articulation of ideas, 'even where they also fluent in English, using their mother-tongue encouraged more spontaneous and open discussions' (Barbour, 2007, p. 99). The interviews were then translated into English by an expert translator, and this stage was essential to avoid potential bias caused by the researcher's background and identity as a male Saudi Arabic Muslim (Creswell, 2013).

The primary method of data analysis adopted in this study was 'analytic generalisation', following the principles of grounded theory, or ' .... an inductive approach for generating theories and explanations' (Johnson \& Christensen, 2004, p. 47). The raw data was coded inductively to draw out and describe ideas from the transcripts (Boyatzis, 1998; Guest et al. 2012). Following the argument of Stake (2005) that researchers should find the method that works best for them in data analysis, the analysis of the raw data consisted of eight-step procedures (adopted from Creswell, 2014, Maxwell, 2005; Patton, 2002). These steps included: transcribing the audio tape recording, re-listening to the interviews recording, re-reading the interviews transcriptions, producing the coding, generating themes, revising themes, translating the key themes and findings and finally producing the report.

\section{Findings, Discussions \& Implications}

Six themes emerged from the interviews with the 21 participants. This section starts by a discussion on motivations of returnees to come back to Saudi Arabia, reporting five motivations that encouraged them to return to Saudi Arabia, including: political and economic stability; job security; scholarship conditions that require them to return home after completing their studies abroad; and strong connections between Saudi returnees and their families Sub-themes emerged about preparation for returning home, indicating that there were neither official re-entry preparation programs organised by Saudi government, nor were the majority of Saudi returnees aware of preparation, followed by a portrayal of participants' feelings on returning home and how it varied. While most of the participants were pleased to return to Saudi Arabia, some had mixed feelings, such as being happy to return but sad to leave the host country. The descriptions are followed by an explanation of participants' relationships with their families and friends. For many, the relationships between the returnees and their families become stronger, although the relationships between returnees and their friends vary; however, it turns out to be stronger if both returnees and their friends had 
similar experiences of living and studying abroad. Another sub-theme emerged about the sense of belonging of Saudi returnees, which was not negatively affected by their international experiences.

\subsection{Motivations for Returning Home}

Identifying the characteristics of the re-entry started by addressing the reasons why Saudi international students returned home after completing their studies abroad. In this sub-theme, 11 participants talked about their motivations for returning to Saudi Arabia after finishing their study abroad. Their motivations for returning home were triggered by several factors, including economic and political stability (two participants), job security (one participant), social connections with their families (six participants) and scholarship conditions assuring their return after completing the study period (two participants).

Initially, two participants M1 and M11 mentioned that it was the economic and political stability that motivated them to return to Saudi Arabia. M1 compared the economic and political stability of Saudi Arabia to other countries in Middle East, noting that Saudi Arabia was a comfortable country to live in:

The things that urged me to return home included the stability of the economic and political situation in Saudi Arabia. It is actually better than other countries in the Middle East. Even on the security level, our country is so comfortable, and our position is perfect (M1).

Similarly, M11 said the unstable economic situation and policy encountered in neighbouring countries was the primary factor influencing return and improving their condition in numerous possible ways:

The economic and political stability are considered as pull factors encouraging me and many Saudi students to return to Saudi Arabia. You know, when I look at our neighbouring countries such as Yemen, Syria and Libya and how bad their situations are, especially after the Arab Spring revolutions, I feel like I have a responsibility to go back to Saudi in order to develop the country and contribute to maintaining its stability.

M6 talked about job security as a motivation for returning. Although he enjoyed living in the U.S. during his study, he never thought of taking on American nationality or a green card. He travelled as a teaching assistant and employee and returned to his former job after the scholarship completion. He was confident he would return to Saudi Arabia, as he was happy to resume his position as a member of the teaching staff at Umm Al-Qura University-and satisfied with his salary.

M3 and M4 talked about the conditions of scholarship programs that required students to return and to work for the government upon completing their studies:

As you know, as sponsored students we have to sign a pledge that we have to return to Saudi Arabia and work for the government for the same period of time we remained abroad or otherwise we have to pay back all the money that has been paid by the government for our study. In fact, I cannot pay back all the money, as it was too much. That is one of the reasons why I have to return to Saudi (M4).

Six of the participants - M8, M10, M13, F4, F7 and F8 - then talked about social connections with their families as motivations for returning home, and they explained how difficult it was for them to be away from their families during the scholarship period. Therefore, they were keen to return home to be with their families. For example, F7 said she never thought about staying in Britain after completing her study, as she cannot live far away from her family:

Really, I never thought about stability in Britain. I had to return because we, as Saudis, are sociable people. I cannot live far away from my family; I have to see them every day or at least every three days!

Moreover, F4 and F8 stated their strong social connection with their families was a main motivation for them to return. Contacting her family daily via Skype while abroad is one sign of such strong social connection, as narrated by F4:

We have strong family connections. Even when I was abroad, I used to contact them daily via Skype. I did not imagine myself living away from them. That's why I was enthusiastic to return home to live the rest of my life close to my family.

Another sign of strong social connection between returnees and their families was mentioned by F8, where being away of her family affected her negatively. Therefore, she worked hard and finished her study quickly to re-connect with her family: 
Frankly, being away from my family has a really negative impact on me. Since my childhood, I haven't been away from them. We used to spend all our time together. That's why I studied very hard in the U.K. I completed my Masters in one year and finished my Ph.D. in three years to return to Saudi and re-connect with my family.

The findings of this sub-theme indicated that Saudi international students differed from international students from other countries who preferred to reside in a host country after completing their study abroad (Bass, 2006; Beverley, 2007; Patton, 2002; Hawthorne \& Hamilton, 2010). More than half of the participants,), stated their desire to return to Saudi Arabia after finishing their studies. Although some other participants did not explicitly express their desire to return to Saudi Arabia, they also did not mention that they intended to remain in their host countries. The motivations for returning home can be classified as either country-related, such as political and economic stability, job security and scholarship conditions that require them to return home once they had completed their studies, or cultural factors like strong connections between them and their families which urged them to go back and live close to their families.

From a political perspective, political stability was one of the motivating factors encouraging Saudi international students to return to the country after completing their study abroad. The regime in Saudi Arabia is considered as a monarchy, where the King manages the affairs of the State. He is also the Prime Minister, who has the ultimate power to make decisions regarding the state. Therefore, it can be said that many Saudis highly respect the King and obey whatever decisions he makes. As a whole, until now Saudi Arabia is still politically stable compared to the surrounding countries, even during the Arab revolutions or the so-called 'Arab Spring' of 2011. In the Arab Spring in 2011 people from countries such as Tunisia, Libya, Egypt, Syria and Yemen demonstrated against their political regimes and called for changes because of the corruption among these governments and leaders. However, the Saudi Arabia regime was immune to these revolutions. To conclude, although the political system in Saudi Arabia differs from many democratic regimes in the world, there is a stability of the Saudi regime and its smooth transition from a king to his crown prince. Consequently, this political stability was one of the motivations for Saudi international students to return to Saudi Arabia after completing their studies overseas.

On the economic side, the economic stability and job security have been mentioned by the participants as motivations to return home. To contextualise, the beginning of the establishment of Saudi Arabia was difficult and problematic as it was initially an area without natural resources. The society as whole was very poor, before the discovery of oil in the eastern part of the country in 1938. This discovery helped the country transfer from being one of the poorest countries to being one of the richest countries in the world (Bukhari\& Denman, 2013). Oil has become the main source of income for Saudi Arabia, which accounts for more than 90 per cent of the country (General Authority for Statistics, 2017). By the end of July 2014, the Saudi economy reached the position as the third largest global economy in total reserve assets, with total reserves including gold 738 billion dollars, after China and Japan. It is also ranked third in the world in the current accounts surplus, where surplus amounted to 132 billion dollars, after Germany and China. The Saudi economy is among the top 20 in the world (Al-Arabiya, 2014). This economic power has enabled the government to attract citizens to work in government sectors, which are characterised by job security, high salaries, and annual bonuses for all employees, as well as a flexible work system. Therefore, it was not surprising that most Saudis prefer to work in government sectors (Ajel, 2016).

The most frequent motivation was social connections, which were mentioned by six participants. This motivation might be understandable for those who know the cultural context of Saudi Arabia, which gives high status to social connections, especially for family. Ibn Sonaitan (2008) described the important role of the extended family in Arab culture in general, and in Saudi culture in particular. He referred to a popular statement among Saudis saying, for the sake of family everything must be sacrificed. Therefore, it is common that Saudis do not prefer to be separated or live far away from their families. For this reason, they try to have jobs which are close to their families which was the main motivation for Saudi international students to return to their home country after completing their studies abroad.

This research outcomes, showing that most Saudi international students preferred to return home after completing their studies abroad, differ from previously published studies (Bass, 2006) which showed that most of Indian international students preferred to stay in Australia subsequent to their completion of study and felt reluctant to go back home. Nevertheless, this study's results are consistent with Gill's (2010) findings indicating that participants had a preference to return home to develop their country and none intended to emigrate. As most Saudi returnees are motivated to return to Saudi Arabia, it was anticipated that the motivations mentioned in this sub-theme, such as political and economic stability, job security and social connection with their families, could help them to re-adjust easily after re-entry. 


\subsection{Preparing for Returning Home}

The findings about the re-entry experiences showed that none of the participants mentioned any formal programs to prepare them to return, nor did they join any personal returning program, except for one participant M7, who had undertaken some reflection and self -preparation:

Frankly, after submitting the PhD thesis to the examiners, I began during the three months to think how to prepare myself for return. At night, I sat with my wife to write about the expected problems that may face us, and how to overcome them, such as housing, financial matters, and dealing with things at family level.

The importance of preparing international students for return is crucial (Anh Le, 2014; Arthur, 2003; Jung, Lee \& Morales, 2013; Kostohryz et.al, 2014, McDermott-Levy, 2013). The results of this sub-theme are both unexpected and expected at the same time. It was unexpected because previous studies Cox, 2006 and Pollis, 2012, showed that organisations or universities sending students abroad provided some resources and workshops to prepare them for returning home. However, this study found that neither Saudi cultural organisations in host countries nor universities in Saudi Arabia provided any resources or workshops for re-entry preparation. These results were expected because it supported the idea that the majority of returnees were lacking awareness on the importance of re-entry preparation (Pollis, 2012). Having re-visited and re-analysed interview transcripts with M7, who was exclusively aware of the importance of re-entry preparation and had self-prepared, it was found that he was among those who did not experience many challenges compared to other participants of this study. Therefore, this could be evidence about the importance of re-entry training. Consequently, a future recommendation would suggest that policy makers provide re-entry workshops or sessions to prepare Saudi international students for homecoming. The results of this present study can be used by them to provide relevant programs, which may address the particular challenges more effectively. As the findings showed there are no re-entry training programs issued by Saudi government before now, a recommendation is that Saudi returnees initiate their own self-preparation, as M7 did.

\subsection{Feelings on Returning Home}

Approximately half of the participants were happy to be back home. This contented feeling is connected to the first sub-theme; the motivation for going home is due to their re-connections with families and friends, as well as a sense of achievement (e.g. by obtaining international certificates). They felt enthusiastic about their careers and giving back to the country that sponsored them and provided them with a chance to study abroad. However, nine participants mentioned that their feelings were a mixture of happiness about being back and sorrow about leaving the country where they had stayed for years of study, and they were worried about re-adaptation to family and home culture. One participant mentioned that she was actually sad to return home.

Many participants described their feelings as full of happiness about returning home. F2 was pleased to return home because she returned with the achievement she had hoped for:

Frankly, when I was returning, I was so happy to come back because I could achieve success and get the Masters. When I was in the undergraduate stage, I looked towards the Masters as a very hard stage. I wondered, "Can I complete postgraduate studies?" I was so happy to overcome my fears, achieve the degree and return to my family!

M9 felt happy and enthusiastic about his job and giving back to Saudi:

My feeling was so wonderful. I was happy about the achievement. Thanks to Allah, I have achieved the mission and got the academic degree. Nothing hindered me to reach my aim. I also felt enthusiastic about jobs and new capability; I am going to be a university professor. I felt it is time to give back to the country that sponsored my studying abroad.

Other participants such as F5, F8 and M5 mentioned several reasons for why they felt delighted to go back to Saudi Arabia. For instance, F8 felt happy because she was returning to a home where she always felt safe:

I was very happy to return to Saudi Arabia for several reasons, like achieving Ph.D. from a developed country, re-connecting again with my family and friends. Most importantly, I want to settle. You know, during living abroad, I wasn't settled, always feeling, this isn't my home. Saudi Arabia is my home where I always feel I am safe.

F5 was happy because returning home for her is like a harvest time, reaping the rewards of working hard during studying abroad:

When I returned, I felt that this is the harvest time. I was happy because I didn't return with Ph.D. only. Rather, I participated in different conferences, attended training courses. I was happy to return to benefit my community. 
Being under pressure of whether or not he could complete his Ph.D. was the source of feeling happiness for M5, because he achieved his goal:

My feelings about the re-entry were full of happiness. Let me tell you something. Before travelling for studying abroad, a colleague said, "if you return without Ph.D., no one will give you much respect here in the university". So, I was under pressure and worried about whether I could complete my Ph.D. or not.

On the contrary, nine participants said that their feelings about returning home were a mix of pleasure about coming back home and sorrow to leave the hosting country, as described by M2, M4 and F4. For example, M4, who lived for seven years in the U.K., was happy about his graduation and returning home on one hand; however, on the other, he was very sad to leave his friends in the U.K:

In fact, I had mixed feelings; happy about graduation and getting the certificate, pleased to return home and see my parents, and at the same time very sad to leave my friends in the U.K.

Likewise, M2, who lived in Australia for eight years, described this mixture of feelings as strange:

I had mixed feelings upon returning home. It was a strange feeling; from one side, I was full of happiness about achieving the required degree for my scholarship and nothing prevented me from acquiring it. On the other side, I couldn't believe that I would leave Australia; the country that I loved and lived in for years.

F4, who lived for seven years in Australia, was happy that her father was proud, but at the same time sad about missing the place where she felt independent:

Upon returning home, I felt mix feelings; meaning I was happy to tell my father that see, I have achieved my goal. At the same time, I yearned for Australia; the place where I had learned and lived independently.

A similar mixture of feelings was expressed by M3, M6, M9, M9, M12 and F7. M3, who lived for seven years in Australia, was happy to return, having achieved something he thought was impossible for him, but also sad to leave Australia:

I had a mixture of happy and sad feelings. Sure, I was happy to achieve an objective I had seen as impossible, especially with the great obstacles I faced during the language stage. Nevertheless, I was sad to leave Australia, which I loved and lived in happily.

M6, who lived eight years in the U.S., was proud of himself and his achievement and unhappy about leaving the U.S.:

When I returned, I was proud of myself that I had achieved something that was not easy to achieve i.e. Ph.D. Frankly, it was like mixed feelings. I was also unhappy for leaving the U.S. where I lived for eight years. Additionally, I was enthusiastic to start my new career as a lecturer to benefit my country that sponsored me and paid hundreds of thousands of dollars during my study.

M12, who lived six years in Australia, described his feeling as being in-between:

Feelings of returning home after spending years abroad were strange. I had mixed feelings about the re-entry because I had adapted myself to live in Australia and was also enthusiastic to return and improve my country. Actually, my feeling was like being 'in between'.

The findings of this sub-theme, that showed most of the participants were happy to be back home, are in line with the work of Gill (2010), stating that returnees have positive feelings about their homecoming, such as happiness about reuniting with family and friends. Conversely, these findings contradict Ryan and Twibell (2000), whose findings asserted that the process of returning home is the greatest stressor for international students, as experienced by some college students who participated in a semester or two semesters in an international students' exchange program. The contradictory results of this study in comparison to Ryan and Twibell's study (2000), were probably related to the time-frame of both studies, as the data of their study were collected in 1994 to 1995, when the communication technology was not as advanced, accessible, and affordable as it is now. The weak contact between participants of Ryan and Twibell's study (2000) and their heritage culture while they were abroad was the reason for feeling stressed about returning home, as they did not know what to expect and they were not aware of changes in their host country during their living abroad. The strong contact between the participants of this study and their heritage culture, due to using the available communication technology, might be the reason for making most of the participants feel happy about returning home to their familiar home culture.

Just under half of the participants experienced a mixture of feelings about the re-entry; happy feelings on being home and being sad to leave the host countries. This result may be explained by the fact that the nine participants lived 
between six and nine years abroad. To be more specific: M8, M9 and M12 lived six years abroad; F4, M3 and M4 lived seven years abroad; M2 and M6 lived eight years abroad; and F7 lived nine years abroad. During these years of living abroad they adjusted well and built good friendships with people in their host countries. Therefore, they were sorry to lose the host countries' lifestyles and their friends but not sad about not wanting to go home. This part of the findings supports Arthur (2003), who stated that returning feelings were generally combined with a sense of loss about leaving the host country's lifestyle. An exception was F3, who felt sadness upon her return and did not show any feelings of happiness about returning home, compared with the other participants. By re-analysing her interview transcripts, these feelings could be explained by several reasons, such as her unstable relationship with family and friends, and her unemployment issues in Saudi Arabia upon her re-entry. An implication of the results in this sub-theme was that the awareness of such feelings on returning home might be helpful in approaching and providing suitable help for them if necessary. Moreover, the returnees themselves also need to be mindful that such feelings are normal and will generally dissipate over time.

\subsection{The Nature of Relationships with Family}

Referring to the definition of family in this study stated that their relationship with their families did not change. It even became stronger with their parents after being away from home on the scholarship. They also mentioned happiness and feelings of family pride towards them. However, only one female participant - F3 - expressed an unstable relationship; with her mother.

F8 said that her relationship with her family had improved because she missed them for years when she was studying abroad, and after returning, she visits them daily. M10 reported the improvement in his relationship with his family describing his family's happiness on his return as like a King coming to visit them at home. Other participants, such as M3, M5, M7, and F7, described their families' pride in their achievements. Therefore, their families held a big party on their arrival and celebrated their success in acquiring the academic degree. Participants also stated that their tribes, or (extended families) were also happy about their achievements and showed respect for their positions as teaching staff in the university, as described by M4:

When I came back, my uncles, brothers, and family held a great celebration on my obtaining the PhD. Now, they consult me on the tribe's affairs despite my young age. There are also people older than me who consulted me because I got the PhD from abroad.

The following extracts gained from the interviews showed the strong relationship between participants and their families after returning from studying abroad. For instance, M2 missed his family while abroad and recognised their value. Therefore, he maintained a good relationship with them after returning home:

While studying abroad, I missed my family so much. Frankly, we don't know the value of things until we miss them. I missed my family and I realise their values and I can say they missed me as well. After returning to Saudi, I recognise the importance of my family and maintain good relationships with them.

M6 narrated how his family members, especially his father, were proud of him and his achievement:

I feel like my relationship with my family is very strong. My father for example, is proud of me. So, when he introduces me to his friends, he would say, my son (M6) holds a Ph.D. and he is a teaching assistant at Umm Al-Qura University. I feel all my family members are happy about my re-entry and proud of me and I am happy to be close to them.

M11 related the reason for a strong relationship between him and his family as having similar experiences of being abroad and returning home:

My relationship with my family is strong as my family is an educated family. My cousins and nieces are studying abroad. And some of my relatives are returnees from studying abroad, so we have common interests for all of us.

M12 mentioned how his relationship with his family has improved after returning home as they perceived him as an educated person:

I see my relationship with my family has improved. They look at me as an educated person. So, and they respect me and consult me in their affairs. I feel like I have a special relationship among other brothers who don't study abroad.

Only one participant, F3, reported that her relationship with her mother was now unstable because she would have liked to be as independent as she was in Britain, but her mother did not accept such behaviour:

Really, my relationship with my mother is unstable, she does not accept me being independent and she would always get angry when I told her that. However, it is my simple right to say "yes" or "no". For example, I got a job in 
Jeddah, but my mother refused to let me take it and said, "How can you leave us and live in Jeddah alone?" I said I was in Britain alone for several years, but she said that was in Britain but here is different. On the other hand, my father was completely different. He said, "I trust you. You stayed in Britain for years alone". I feel that my father is proud of my achievement, but my mother feels that I am rebellious.

As this sub-theme showed, 20 of the participants reported a good relationship with their families. This result was expected because of the Saudi cultural context that gives great status to the family and for individuals who have excellent relationships with their families. There are similarities between this result and the result of Gill (2010), which found a good and warm relationship between returnees and their families. However, this finding does not support the study of Butcher (2002) that found unstable relationships between returnees and their families. It should be noted that Butcher's study (2002) was conducted with East Asian returnees from studying in New Zealand and included returnees from Hong Kong, Singapore and Thailand. The results detailed the source of this unstable relationship between returnees and their families, which was seen as culturally bound. The common cultural context and values in these countries are Confucian beliefs which state the importance of family ties (Blair \& Qian, 1998). Nevertheless, as students studied in New Zealand, they converted to Christianity. However, upon their re-entry their parents did not appreciate this change and prevented them from going to church.

Regarding the one participant (F3) who reported an unstable relationship with her family, particularly her mother, further analysis found this instability related to her mother's illiteracy and dependence on conservative family viewpoints. F3 said that her mother was illiterate and did not accept her independence or autonomy when F3 decided to move to another city for a new job. Another explanation might refer to F3's strong personality, as she experienced difficulties with her friends as well. These soft relationships assisted returnees to feel they were welcome back into their home country and helped them re-adapt easily. However, F3 can be seen as an exception from this general view. An implication of these results was that the good relationship between returnees and their families is critical in facilitating the re-adjustment of returnees. Therefore, all returnees, regardless of their home countries, should maintain a good relationship with their families during their time abroad in order to help them to re-adapt easily upon the re-entry.

\subsection{The Nature of Relationships with Friends}

Participants' responses varied with regard to their relationships with friends. Five participants talked about unstable relationships with their friends. Eight participants reported good relationships with their friends when they mutually experienced living and studying abroad and six participants said that they were mostly not sociable and did not really have friends.

F1, F3, F6, M6 and M8 reported an unstable relationship with their friends. F3, for instance, noticed suspicious views from her friends toward her. Her friends also sensed negative impacts of being abroad on her identity, and this becomes a source of unstable relationships with them:

Unfortunately, I do not have friends as I did before. Some of my old friends abandoned me when knowing that I had travelled abroad. They thought that I became irrelevant to their identity. Now, I need to find them again. I was afraid that getting a certificate from abroad represents a barrier between my friends and me.

Moreover, M6 talked about jealousy some friends have expressed to him as a source of unhealthy relationship:

I will try to be honest with you. There are people whom I consider as friends. However, I feel like they are jealous because they didn't have the same opportunity of studying abroad. When we are in our monthly gathering and they see that people respect me, I feel their eyes trying to say to people 'hey, why you are giving this guy more attention?' (M6).

F1 and F6 lost communication with some friends because they did not contact them for long time:

I lost my friends, maybe because of life duties. I went to Australia and some of them got married and had children. Now, they are busy with their lives and I am busy with my own life. I am just asking why they didn't contact me when I was abroad and when I returned. They didn't even congratulate me upon my graduation. I don't know why (F1).

M3, M4, M9, M11, F2, F5, F7 and F8 reported good relationships with their friends because their friends also used to study abroad with them:

I feel that my relationships with friends did not change. Frankly, my friends are mainly those who studied abroad and have the same experiences of studying abroad and returning home (M11).

I still maintain good relationships with my friends because we have similar ways of thinking. So, there were no sources for conflicts between us (F2). 
M4, mentioned how expanding social communication means, such as WhatsApp, helped him keep up good relationships with his friends:

I am a sociable person. I appreciate friendships. I still have good relationships with my friends, even those who used to study with me in the English language centre in the U.K. I have good connections with them, especially nowadays with WhatsApp, we have many groups for friends.

F7, reported good relationships with her friends and meeting with them in Mecca during holidays:

I still have good friendships with my friends, especially those who I met in the U.K. Still, we keep in touch and meet in the holidays when they come to visit the holy mosque in Mecca (F7).

M1, M7, M12, M13, F4 and F5 said that they are not sociable people and consequently they do not have people they can call friends. For instance, M12, described himself as a non-sociable person who does not have real friends:

I am not a social person. I really don't have people who I can call friends, maybe because my requirements of friendships are high!

Similarly, F4, mentioned that she mainly does not have many friends:

I have many colleagues because I studied in different cities such as Riyadh, Jeddah and Mecca. However, I don't have many friends. It might be because I'm not such a sociable person (F4).

It is found in this sub-theme that 8 of the participants reported a good relationship with their friends after returning home. This part of the result contradicts the findings of Allison et al. (2011) in the ways that they reported unstable relationships between returnees and their friends because friends seemed to be uninterested in the existing experiences of studying abroad and returning home. This result may be justified by the fact that all eight participants reported that their friends are those who have had similar experiences of studying abroad and returning home. Thus, it could be argued that friends might be interested in listening to the experiences of returnees if they have similar experiences.

Five participants reported unstable relationships with their friends after returning home due to non-acceptance of change (F3 and M8), jealousy (M6), or loss of contact for a long period (F1 and F6). This finding matches those observed in previous studies, such as Brabant, et.al.-(1990) and Butcher (2002), who found that returning from studying abroad meant they had lost some friends However, six of the participants mentioned that they were not particularly sociable and did not have or need many friends. This result might be related to the participants' definitions and views of friendship, as they said: We have colleagues but not friends.

In the light of the findings of this sub-theme that showed eight returnees reporting a good relationship with those friends who had similar experiences of studying abroad and returning home, it would be beneficial for returnees to establish an association or a union for Saudi returnees. Regular meetings among the returnees can be useful to exchange their experiences and provide suggestions for the newly returned. The policy makers can also benefit from these unions or associations to assist with establishing official preparation programs for other returnees.

\subsection{Sense of Belonging}

The findings showed that five of the participants felt a high sense of belonging to Mecca. These participants are F3, F8, M8, M10, and M13, all expressed high senses of belonging, as F8 stated how the spiritual relationship to Mecca helped to experience a high sense of belonging:

We, as Saudis, differ from most international students who aim to settle in the host country, as we have a spiritual relationship with the place where we live. I live in Mecca and feel that it is a great blessing from Allah. When I returned from the U.K, I felt like finally this is my home! This is the place that I feel I belong.

M13 added that Mecca residents could not live for a long time away from Mecca. He described the residents as fish and Mecca as water. Meaning, similar to fish that cannot live for a long time outside the water, Mecca residents cannot live outside Mecca and prefer to return to it:

It is said that the Mecca people are like fish; cannot live out of water. Similarly, we cannot live out of Mecca. I hardly stayed in the U.K. I was keen on spending the annual vacations in Saudi Arabia. Sometimes I returned to Saudi Arabia twice a year.

Similar to these words, M10 said:

I have non-Saudi colleagues who came to America to settle permanently but not me. I love Mecca and even if I have been offered a job away from Mecca, I will not accept it. I am like a fish and Mecca is the sea. When I left Mecca to 
go to America for studying, I became ill and remained in bed for a month. I was so sick, "bedridden" as they say.

Accordingly, these findings that showed the sense of belonging of some Saudi returnees who had not been completely affected by studying abroad, did not support the results of Gaw (2000), which showed that one of the problems experienced by American college students returning from studying abroad was the feelings of not belonging to their home country any longer. A possible explanation for this result might be related to the motivations for returning home, such as political and economic stability and job security, which facilitated their re-entry and increased their sense of belonging. Moreover, it might be related to Saudi Arabian recognition of returnees themselves, through sponsoring their studies overseas and providing them with a chance to acquire high-level certificates from developed countries. Therefore, they can have a high sense of appreciation, belonging and giving back to the Saudi homeland that sponsored their studying abroad.

\section{Conclusion, Limitations \& Directions for Future Research}

This research aimed to answer this research question: How do Saudi returnees describe the characteristics of their re-entry to Saudi Arabia after studying abroad? The study presented and discussed six sub-themes answering this research question. The findings showed several motivations that encouraged Saudi international students to return home. These motivations were either country-related, such as political and economic stability, job security and scholarship conditions that require them to return home once they had completed their studies, or cultural factors like strong connections between them and their families, which urged them to go back and live together with families.

The findings designated that there were neither official re-entry preparation programs organised by the Saudi government nor were Saudi returnees aware about the need for preparation, except for one participant who had done some self-preparation. In terms of returnees' feelings about returning home, the findings showed various emotions, yet generally, most participants were pleased to return to Saudi Arabia. Moreover, the findings described that 20 of 21 participants expressed an intense relationship with their families after returning home. Nevertheless, their relationship with friends is, on the other hand, less powerful. The relationship turns out well and is warm if both Saudi returnees and their friends had similar experiences of studying abroad. Finally, the findings of this study also demonstrated that the sense of belonging Saudi returnees' experience, had not been completely affected by studying abroad.

The limitations of the research could be summarised as follows: First, this study focuses on one research setting, which is at Umm Al-Qura University in Mecca, Saudi Arabia - one of 34 universities in the country. This university was chosen as the research site because Mecca is considered as a multicultural city, thus it would be easier to find participants who could represent the diversity of Saudi Arabia. Nonetheless, they cannot represent all potential participants from different universities around Saudi Arabia.

Second, considering the small size of the participant sample from one particular university, the findings are not generalizable. A qualitative research project like a case study is indeed a poor basis for generalisation (Gerring, 2006; Stake, 1995; Yin, 2009). The generalisation in this study takes the form of advice to other Saudis returning from studying abroad in general and those who are working in the territory of education in particular. Finally, the data analysis concentrates on the emerging themes from the interviews rather than detailed descriptions for each participant experience. The analysis technique might be considered as a drawback for this study. Although such technique for data analysis provided an overall clear structure of the findings, the participants' complete stories of their re-entry experiences to Saudi Arabia were not specifically addressed. Therefore, this limitation provides a direction for further research to address it.

The following are suggestions for future research. First, this study employed qualitative methodology with a small sample of Saudi returnees. Future studies could use quantitative methodology which could involve a larger sample of Saudi returnees to enhance the generalisation of data. The findings of this study are beneficial for quantitative researchers to develop their questionnaires. Second, the research sample of this study was restricted to Saudi returnees who completed their postgraduate studies abroad. 29 per cent of the participants $(n=6)$ believe that younger returnees faced greater challenges than older ones. Further work is needed to investigate the re-entry experiences of younger returnees (i.e. those who graduated from their bachelor's degrees). Bearing in mind that most of these young returnees are unemployed, exploring their experiences will also be valuable to gain understanding of different experiences for different ages. Third, as this study was limited to returnees working in academia, particularly in Umm Al-Qura University, some research questions remain unanswered, such as 'What about the characteristics of the re-entry of academics in different universities campuses, particularly in rural campuses?', 'What about the characteristics of the re-entry of returnees working in health sectors or military interfaces?'. Future studies are 
expected to cover larger fields of work, such as government officials, health, military, and so forth. Covering these areas is expected to open new doors for different re-entry experiences.

\section{References}

Ajel. (2016). Why Saudi prefer to work in government sectors. Ajel. Retrieved from https://ajel.sa/local/1687171

Alhazmi, A. \& Nyland, B. (2015). Contextualization of Saudi international students' experience in facing the challenge of moving to mixed gender environments. American International Journal of Contemporary Research, $5(2), 87-97$.

Alhazmi, A. A. (2015). What it looks like to be in a mixed gender society: The essence of transitioning experience from gender segregated environment to mixed gender environment. Journal of Foreign Languages, 3(1), 49-57. https://doi.org/10.15640/jflcc.v3n1a7

Alika, H. \& Ohanaka, B. (2013). The role of counselling and parental encouragement on re-entry of adolescents into secondary schools in Abia state, Nigeria. Research in Education, 89(3), 61-69. https://doi.org/10.7227/RIE.89.1.5

Allison, P., Davis-Berman, J. \& Berman, D. (2012). Changes in latitude, changes in attitude: Analysis of the effects of reverse culture shock - A study of students returning from youth expeditions. Leisure Studies, 31(4), 487-503. https://doi.org/10.1080/02614367.2011.619011

Alsulami, N. (2018). The Challenges of Studying in Australia for Saudis Male International Students. American International Journal of Contemporary Research, 8(2), 17-28. https://doi.org/10.30845/aijcr.v8n2a3

Arthur, N. (2003). Preparing international students for the re-entry transition. Canadian Journal of Counselling, 37(3), 173-185.

Baas, M. (2006). Students of migration: Indian overseas students and the question of permanent residency. People and Place, 14(1), 8-23.

Brabant, S., Palmer, C. \& Gramling, R. (1990). Returning home: An empirical investigation of cross-cultural re-entry. International Journal of Intercultural Relations, 14(4), 387-404.https://doi.org/10.1016/0147-1767(90)90027-T

Boyatzis, R. (1998). Transforming qualitative information: Thematic analysis and code development. Thousand Oaks, CA: Sage.

Brown, B. (2010). Social hostility and the "dropout" syndrome: Leadership assisting youths' re-entry into school? Educational Review, 62(1), 53-67. https://doi.org/10.1080/00131910903469577

Bukhari, F. \& Denman, B. (2013). Student scholarships in Saudi Arabia: Implications and opportunities for overseas engagement. In A. Abouammoh, L. Smith \& SpringerLink. (Eds.), Higher education in Saudi Arabia: Achievements, challenges and opportunities (pp. 151-158). New York: Springer Netherlands.https://doi.org/10.1007/978-94-007-6321-0_14

Butcher, A. (2002). A grief observed: Grief experiences of East Asian international students returning to their countries of origin. Journal of Studies in International Education, 6(4), 354-368. https://doi.org/10.1177/102831502237641

Caine, B. (2009). Friendship: A history. London, Oakville, CT: Equinox Pub.

Casinader, N. (2012). Cultural perspectives, thinking, educators and globalisation: A critical analysis of the future problem solving program: University of Melbourne, Melbourne Graduate School of Education.

Casinader, N. a. (2014). Culture, transnational education and thinking: Case studies in global schooling. New York: Routledge https://doi.org/10.4324/9781315857725

Chamove, A. \& Soeterik, S. (2006). Grief in returning sojourners. Journal of social sciences, 13(3), 215-220. https://doi.org/10.1080/09718923.2006.11892552

Christofi, V. \& Thompson, C. L. (2007). You cannot go home again: a phenomenological investigation of returning to the sojourn country after studying abroad. Journal of Counseling \& Development, 85(1), 53-63. https://doi.org/10.1002/j.1556-6678.2007.tb00444.x

Cox, L. (2006). Going home: Perceptions of international students on the efficacy of a re-entry workshop. University OF Southern California. ProQuest Dissertations and Theses.

Creswell, J. W. (2014). Research design: Qualitative, quantitative, and mixed methods approaches (4th ed.): 
Thousand Oaks, CA: Sage Publications.

Darlaston-Jones, D. (2007). Making connections: The relationship between epistemology research methods. The Australian Community Psychologist, 19(1), 19-26.

Dettweiler, U., Unlu, A., Lauterbach, G., Legl, A., Simon, P. \& Kugelmann, C. (2015). Alien at home: Adjustment strategies of students returning from a six-month oversea's educational programme. International. Journal of. Intercultural Relations, 44, 72-87. https://doi.org/10.1016/j.ijintrel.2014.10.005

Dickey, W. \& Klingele, C. (2004). Promoting public safety: A problem-oriented approach to prisoner re-entry. Prisoner re-entry and community policing: Strategies for enhancing public safety. Washington, D.C.: The Urban Institute.

Flick, U. (2006). An introduction to qualitative research (3rd Ed.). London: Sage Publications.

General Authority for Statistics, S. A. (2017). The original website. Retrieved from https://www.stats.gov.sa/en

Gill, S. (2010). The homecoming: An investigation into the effect that studying overseas had on Chinese postgraduates' life and work on their return to China. Compare: A Journal of Comparative and International Education, 40(3), 359-376. https://doi.org/10.1080/03057920903464555

Guest, G., MacQueen, K. M. \& Namey, E. E. (2012). Applied thematic analysis. London: Thousand Oaks, CA. Sage Publications.https://doi.org/10.4135/9781483384436

Hadis, B. F. (2005). Why are they better students when they come back? Determinants of academic focusing gains in the study abroad experience. Frontiers: The Interdisciplinary Journal of Study Abroad, 11, 57-70. https://doi.org/10.36366/frontiers.v11i1.151

Hattery, A. \& Smith, E. (2010). Prisoner re-entry and social capital: The long road to reintegration. Lexington Books.

Hawthorne, L. \& Hamilton, J. (2010). International medical students and migration: the missing dimension in Australian workforce planning. The Medical journal of Australia, 193(5), 262-289. https://doi.org/10.5694/j.1326-5377.2010.tb03903.x

Ibn Sonaitan, M. (2008). Saudi Arabia policy and tribes (1st Ed.). Beirut: Arabic company for research.

Jandova, P. (2014). Reverse culture shock: Czech students returning home from the United States. Place: Masarykova University, Pedagogical faculty.

Johnson, B. (2014). Educational research: Quantitative, qualitative, and mixed approaches (5th Ed.). Thousand Oaks, CA: Sage Publications

Jung, A.-K., Lee, H.-S. \& Morales, A. (2013). Wisdom from Korean re-entry counselling professionals: A phenomenological study of the re-entry process. International Journal for the Advancement of Counselling, 35(3), 153-171. https://doi.org/10.1007/s10447-012-9174-4

Kartoshkina, Y. (2015). Bitter-sweet re-entry after studying abroad. International Journal of Intercultural Relations, 44, 35-45. https://doi.org/10.1016/j.ijintrel.2014.11.001

Larson, D. (2006). Here we go again: How a family's cross-cultural and repatriation adjustment relates to the employee's receptivity to future international assignments. SAM Advanced Management Journal, 71(2), 46-57.

La Vigne, N. (2010). Prisoner re-entry and community policing: Strategies for enhancing public safety. Washington, D.C.: Urban Institute, Justice Policy Centre.

MacDonald, S. \& Arthur, N. (2004). Employees' perception of repatriation. The Canadian Journal of Career Development, 2(1), 3-11.

McDermott-Levy, R. (2013). Female Arab-Muslim nursing students' re-entry transitions. International Journal of Nursing Education Scholarship, 10(1), 163-170. https://doi.org/10.1515/ijnes-2012-0042

Miller, J. \& Glassner, B. (1997). The 'inside' and the 'outside': Finding realities in interviews. Qualitative research, 99-112.

Ministry of Education, S. A. (2018). The original website. Retrieved from https://www.moe.gov.sa/en/Pages/default.aspx

Mukthyala, S. (2013). Lived Experiences of Indian International Students: Migration, Acculturation, and Resilience. ProQuest LLC. 789 East Eisenhower Parkway, PO Box 1346, Ann Arbor, MI 48106. 
Musita, R., Ogange, B. \& Lugendo, D. (2018). A second chance to dream: Initiating ODeL in secondary school re-entry programs for young adult secondary school dropouts the case of Mumias District, Western Kenya. Distance Education, 39(1), 122-133. https://doi.org/10.1080/01587919.2018.1429896

Novera, I. A. (2004). Indonesian postgraduate students studying in Australia: An examination of their academic, social and cultural experiences. International Education Journal, 5(4), 475-487.

Patton, M. Q. (2002). Qualitative research \& evaluation methods (3rd Ed.). Thousand Oaks, CA: Sage Publications.

Pedlar, A., Arai, S., Yuen, F. \& Fortune, D. (2018). Community re-entry: Uncertain futures for women leaving prison. London: Routledge.https://doi.org/10.4324/9781351204477

Pitts, M. J. (2016). Sojourner re-entry: A grounded elaboration of the integrative theory of communication and $\begin{array}{llll}\text { cross-cultural adaptation. } & \text { Communication }\end{array}$ https://doi.org/10.1080/03637751.2015.1128557

Pollis, J. (2012). Re-entry resources available to university students returning from study abroad programs: A case study. In N. W. Sobe \& T. Williams (Eds.) ProQuest Dissertations Publishing.

Pritchard, R. (2011). Re-entry trauma: Asian re-integration after study in the West. Journal of Studies in International Education, 15(1), 93-111. https://doi.org/10.1177/1028315310365541

Regan, P. (2011). Close relationships. Hoboken: Taylor \& Francis.https://doi.org/10.4324/9780203834749

Ryan, M. E. \& Twibell, R. (2000). Concerns, values, stress, coping, health and educational outcomes of college students who studied abroad. International Journal of Intercultural Relations, 24(4), 409-435. https://doi.org/10.1016/S0147-1767(00)00014-6

Stake, R. E. (2005). The art of case study research. Thousand Oaks, CA: Sage Publications.

Szkudlarek, B. (2010). Re-entry-A review of the literature. International Journal of Intercultural Relations, 34(1), 1-21. https://doi.org/10.1016/j.ijintrel.2009.06.006

The Holy Quran, Q. (2010). The Holy Quran. Medina: King Fahad publication.

Van Geel, A. (2016). Separate or together? Women-only public spaces and participation of Saudi women in the public domain in Saudi Arabia. Contemporary Islam, 10(3), 357-378. https://doi.org/10.1007/s11562-015-0350-2

Walling, S., Eriksson, C., Meese, K., Ciovica, A., Gorton, D. \& Foy, D. (2006). Cultural identity and re-entry in short-term student missionaries. Journal of Psychology and Theology, 34(2), 153-164. https://doi.org/10.1177/009164710603400205

Ward, K. (2017). Rural jail re-entry: Offender needs and challenges. New York: Routledge.https://doi.org/10.4324/9781315469850

Welsh, A. (2015). Long term effects of reverse culture shock in study abroad. In C. Cartwright, M. Sobre-Denton \& M. Vande Berg (Eds.) ProQuest Dissertations Publishing.

Wielkiewicz, R. M. \& Turkowski, L. W. (2010). Re-entry issues upon returning from study abroad programs. Journal of College Student Development, 51(6), 649-664. https://doi.org/10.1353/csd.2010.0015

Yin, R. K. (2014). Case study research: Design and methods (5th Ed.). Los Angeles, CA: Sage Publications.

Young, G. E. (2014). Re-entry: Supporting students in the final stage of study abroad. New Directions for Student Services, 2014(146), 59-67. https://doi.org/10.1002/ss.20091 